American Journal of Applied Sciences 6 (6): 1242-1245, 2009

ISSN 1546-9239

(C) 2009 Science Publications

\title{
Model of High-Temperature Diffusion of Interstitial Silicon Atoms in Silicon
}

\author{
${ }^{1}$ M. Jadan, ${ }^{2}$ A.R. Chelyadinskii and ${ }^{2}$ V.Yu. Yavid \\ ${ }^{1}$ Department of Applied Physics, Faculty of Science, Tafila Technical University, \\ P.O. Box 40, Al-Eys 66141, Tafila, Jordan; On Sabbatical Leave: Department of Physics, \\ Faculty of Science, Jazan University, P.O. Box 203, Abu Areesh, Jazan, KSA \\ ${ }^{2}$ Department of Semiconductors Physics, Faculty of Physics, Byelorussian State University, \\ Pr. F. Skarina 4, 220050 Minsk, Belarus
}

\begin{abstract}
Problem statement: Correct description of the anomalous phenomena determined by selfpoint defects in implanted silicon desires knowledge of their properties. Interstitial $\mathrm{Si}$ atoms themselves display anomalies in their behavior and firstly in existence of two very different values of the diffusion coefficient. Approach: We analyzed experimental results and proposed the model of diffusion of interstitial $\mathrm{Si}$ atoms in silicon in two shapes. Results: At low saturation $\mathrm{Si}$ atoms diffuse as isolated atoms with a low diffusion coefficient $\left(\sim 10^{-12} \mathrm{~cm}^{2} \mathrm{sec}^{-1}\right.$ at $\left.900^{\circ} \mathrm{C}\right)$. At high supersaturation interstitial atoms diffused as $\mathrm{Si}-\mathrm{Si}$ pairs, which had lower activation energy of migration and higher diffusion coefficients $\left(\sim 10^{-7} \mathrm{~cm}^{2} \mathrm{sec}^{-1}\right)$. Conclusion: The high diffusivity pairs were formed when two $\mathrm{Si}$ atoms hit in the same interstice. The atoms were not bound to one another by covalent bond. In a pair atoms were retained by a potential relief of the crystal.
\end{abstract}

Key words: Silicon, ion implantation, interstitial Si atoms, diffusion coefficient

\section{INTRODUCTION}

Point defects in silicon (vacancies and interstitials) play important role in electrical activation and diffusion of implanted impurities, in getter formation, in formation of the secondary damages. These defects substantially reduce the parameters of the devices and the device yield. The process of secondary defect formation is controlled by the diffusion of interstitial $\mathrm{Si}$ atoms. Nevertheless, during three decades there is not being resolved a problem on the high-temperature diffusion coefficient (D) of $\mathrm{Si}$ interstitial atoms in silicon single crystals. In a series of works D was defined to be $\sim 10^{-7} \mathrm{~cm}^{2} \mathrm{sec}^{-1}$ at $900^{\circ} \mathrm{C}^{[1-5]}$. In other data $^{[6-10]}$ a diffusion constant was regarded to be about $10^{-12} \mathrm{~cm}^{2} \mathrm{sec}^{-1}$ at this temperature. It was noted, that the large values of diffusion constants bound in experiments, where high levels of supersaturation by $\mathrm{Si}$ interstitial atoms had been created in a crystal. There was a suggestion, that the traps for $\mathrm{Si}$ atoms were responsible for the decrease of the diffusion coefficient ${ }^{[10]}$. It was argued, that the peak $\mathrm{D}$ values were measured on epitaxial silicon layers, whereas in the Czochralski-grown crystals the diffusion constants had much smaller values. However, it was shown that in these most "dirty" crystals there could be large D values too ${ }^{[11]}$. It was supposed ${ }^{[11]}$, that at high supersaturation the traps were filled by $\mathrm{Si}$ atoms (saturated traps) and afterwards the diffusion constant became high. Such representation required, as the authors ${ }^{[12]}$ mentioned, the existence of time dependence of D. However, experiments ${ }^{[12]}$ have not confirmed such a dependence.

We propose a model explaining the existence of two set of values of $\mathrm{Si}$ interstitial atoms diffusivity in silicon lattice.

\section{MATERIALS AND METHODS}

The diffusivity of $\mathrm{B}$ or $\mathrm{P}$ in silicon is proportional to the self-interstitial concentration. This property is utilized to map the interstitial concentration as function of depth and determine the diffusion coefficient of interstitials. A source of interstitials were oxidation process or $\mathrm{Ar}^{+}$ion implantation ${ }^{[2,9]}$, using $\mathrm{n}$ - and p-type float zone $\langle 100\rangle$ wafers with $\rho_{0}=10-20$ Ohm.cm. Profiles were measured with a spreading resistance technique.

\section{RESULTS}

In Fig. 1 (curve 1) typical dependence of diffusion constant of $\mathrm{Si}$ atoms in silicon versus temperature $\mathrm{D}(\mathrm{T})$ in experiments with low saturation is $\operatorname{shown}^{[9]}$.

Corresponding Author: Muhanad Jadan, Department of Applied Physics, Faculty of Science, Tafila Technical University, P.O. Box 40, Al-Eys 66141, Tafila, Jordan; On Sabbatical Leave: Department of Physics, Faculty of Science, Jazan University, P.O. Box 203, Abu Areesh, Jazan, KSA Tel :+966551569536 
Am. J. Applied Sci., 6 (6): 1242-1245, 2009

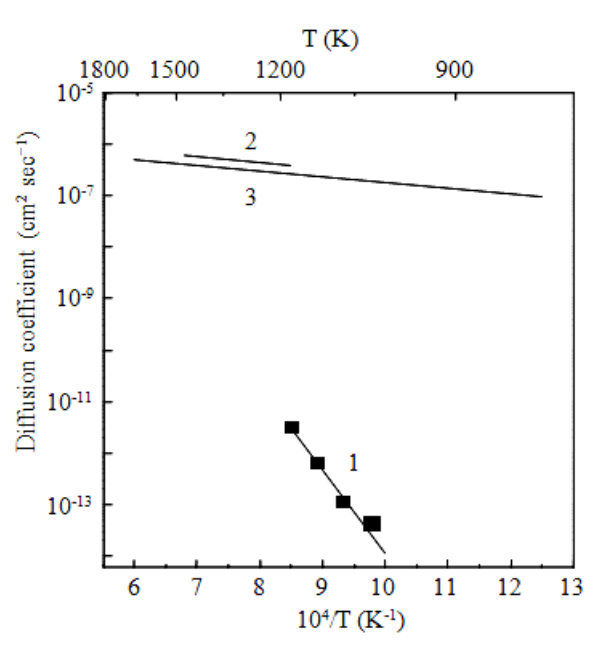

Fig. 1: Temperature dependencies of a diffusion constant of $\mathrm{Si}$ interstitial atoms in silicon. (1): Low saturation ${ }^{[9]}$; (2 and 3): High supersaturation $^{[1,2]}$

In this case, the diffusion constants are not high and the steep dependence of diffusion constant on temperature is observed. At change of temperature on $200^{\circ} \mathrm{C}$ coefficient $\mathrm{D}$ varies on two orders of magnitude. Naturally, it is usual temperature dependence of diffusion constant for elements of medial atom masses in silicon ${ }^{[13]}$.

The curves 2 and 3 in Fig. 1 show dependence $\mathrm{D}(\mathrm{T})$ in silicon crystals with strong supersaturation by $\mathrm{Si}$ interstitial atoms ${ }^{[1,2]}$. In this case $\mathrm{D}$ has high values $\left(\sim 10^{-7} \mathrm{~cm}^{2} \mathrm{sec}^{-1}\right)$ and very feebly depends on temperature. At change of temperature on $300^{\circ} \mathrm{C}$ the diffusion constant varies less, than twice. Determined from the curves $\mathrm{D}(\mathrm{T})$ activation energies of $\mathrm{Si}$ atoms diffusion for cases of weak and strong saturation differ practically on the order of magnitude.

\section{DISCUSSION}

The experimental results on a diffusion of $\mathrm{Si}$ interstitial atoms can be compared with results on a diffusion of implanted phosphorus. It was ascertained that implanted phosphorus in silicon had not only high diffusion constant, but with that the effective diffusion coefficient did not depend on temperature at rapid thermal annealing ${ }^{[14]}$. These anomalies were explained with the help of a diffusion pair from $\mathrm{P}$ and $\mathrm{Si}$ atoms in the same interstice, which were not bound to one another by a covalent bond ${ }^{[15]}$.

By analogy with implanted phosphorus we believe that the accelerated diffusion of $\mathrm{Si}$ atoms is determined by diffusion of them, integrated in a pair Si-Si.

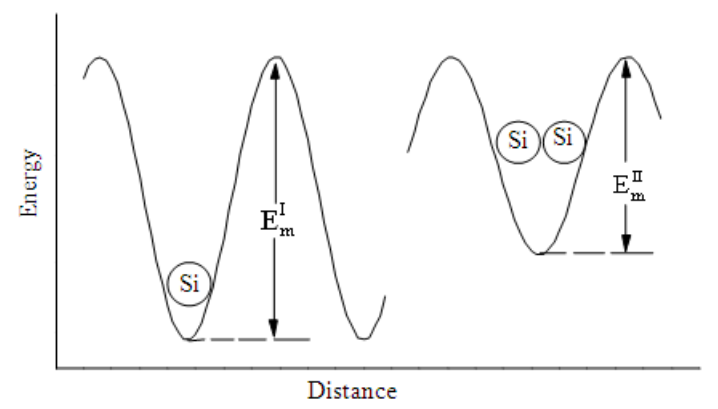

Fig. 2: An energy barrier for migration in silicon lattice of interstitial $\mathrm{Si}$ atoms $\mathrm{E}_{\mathrm{m}}^{\mathrm{I}}$ and $\mathrm{Si}-\mathrm{Si}$ pair from interstitial silicon atoms $E_{m}^{I I}$

This pair is formed at hit in the same interstice of two $\mathrm{Si}$ atoms at their high supersaturation. It is not difficult to estimate that at $\mathrm{Si}$ interstitial atoms concentration of $10^{20} \mathrm{~cm}^{-3}$ concentration of randomly formed pairs is about $10^{18} \mathrm{~cm}^{-3}$. The interstitial atoms in the pair are not bound to one another by chemical covalent bond. The existence of the $\mathrm{Si}-\mathrm{Si}$ pair is determined by a potential relief of the crystal (Fig. 2). In this scheme the quantity of a barrier for migration of an isolated $\mathrm{Si}$ atom is equal $\mathrm{E}_{\mathrm{m}}^{\mathrm{I}}$, for the Si-Si pair- $\mathrm{E}_{\mathrm{m}}^{\mathrm{II}}$. We believe that $\mathrm{E}_{\mathrm{m}}^{\mathrm{II}}<\mathrm{E}_{\mathrm{m}}^{\mathrm{I}}$.

But what is the reason of the lower barrier $E_{m}^{I I}$ for a pair in comparison with barrier $\mathrm{E}_{\mathrm{m}}^{\mathrm{I}}$ for alone $\mathrm{Si}$ atom? A series of interstitial centers $\left(\mathrm{Si}^{-\mathrm{P}} 6^{[16]}, \mathrm{Si}-\mathrm{B} 3^{[17]}, \mathrm{Si}-\right.$ $\mathrm{A} 5^{[18]}, \mathrm{Si}-\mathrm{O} 2^{[19]}, \mathrm{G}-25^{[20]}$ ) of a radiation origin is known in silicon. The interstitial $\mathrm{Si}$ atom is covalently bound to the lattice atoms in these centers. These centers have particular, referenced for each of them, temperature stability limit. But in the literature there are no data to believe that our interstitial $\mathrm{Si}$ atom, diffusing at high temperatures, is covalently bound to a lattice. Placed in an interstice the $\mathrm{Si}$ atom, elastically interacting with lattice atoms, locally distorts a potential relief of a crystal. This elastic interaction determines its standing in an interstice and quantity of the barrier $\mathrm{E}_{\mathrm{m}}^{\mathrm{I}}$. If two $\mathrm{Si}$ atoms are located in the same interstice, the distortion of potential will be more considerable. The elastic interactions of two interstitial $\mathrm{Si}$ atoms with lattice atoms lower depth of the potential well in comparison with alone atom. It is schematically shown in Fig. 2.

When the $\mathrm{Si}-\mathrm{Si}$ pair gains from lattice energy above the barrier $\mathrm{E}_{\mathrm{m}}^{\mathrm{II}}$, it can jump into a neighboring interstice as a whole or the $\mathrm{Si}$ atoms can hop into different interstices (decomposition of the pair), i.e. for the pair the activation energy of migration and destruction has the same value. 
It is easy to show that the temperature independence of experimentally observed diffusion constant of Si interstitial atoms in a pair follows from equality of activation energies of pair migration and annealing. Let speed of generation of $\mathrm{Si}-\mathrm{Si}$ pairs is equal:

$\mathrm{G}=\mathrm{K} \cdot \mathrm{C}_{\mathrm{I}}^{2}$

Where:

$\mathrm{C}_{\mathrm{I}}=$ Concentration of Si interstitial atoms

$\mathrm{K}=$ Speed of reaction

At temperature of a diffusion $\mathrm{T}_{1}$ the number of pairs from interstitial atoms $N$ is equal $G \tau_{1}$, where $\tau_{1}=\tau_{0} \exp \left(\frac{E^{\mathrm{an}}}{\mathrm{kT}_{1}}\right)$-lifetime of a pair. The diffusion flow of $\mathrm{Si}$ atoms $\mathrm{J}_{1}$ in this case is equal:

$\mathrm{J}_{1}=\mathrm{D}_{1} \frac{\mathrm{dN}}{\mathrm{dx}}=\mathrm{D}_{1} \frac{\mathrm{d}}{\mathrm{dx}} \mathrm{G} \tau_{1}$

where, $D_{1}=D_{0} \exp \left(-\frac{E^{\text {dif }}}{k T_{1}}\right)$ is diffusion coefficient of a pair at temperature $T_{1}$. For higher temperature $T_{2}$ the flow of particles $\mathrm{J}_{2}$ will be:

$$
J_{2}=D_{2} \frac{d}{d x} G \tau_{2}=D_{1} \exp \left(\frac{E^{\text {dif }} \Delta T}{k_{1} T_{2}}\right) \frac{d}{d x} G \tau_{1} \exp \left(-\frac{E^{\text {an }} \Delta T}{k T_{1} T_{2}}\right)
$$

where, $\mathrm{k}$ is Boltzmann constant, $\Delta \mathrm{T}=\mathrm{T}_{2}-\mathrm{T}_{1}$. The flows $\mathrm{J}_{1}$ and $\mathrm{J}_{2}$ are equal at equality of activation energies of diffusion $E^{\text {dif }}$ and annealing $E^{\text {an }}$ and by virtue of feeble temperature dependence $\mathrm{D}_{0}$ and $\tau_{0}$ in comparison with temperature dependence of the exponential terms in D and $\tau^{[21]}$. As a result, the experimentally observed diffusion constants of $\mathrm{Si}$ atoms should be independent on temperature.

On experiment, nevertheless, dependence $\mathrm{D}$ on temperature, though feeble, exists (Fig. 1, curves 2 and 3). It is possible to explain such weak dependence $\mathrm{D}$ on temperatures if to take into account the contribution to a diffusion of $\mathrm{Si}$ isolated interstitial atoms. Their diffusion coefficient is much less than a diffusion coefficient of Si-Si pairs. But as the number of isolated interstitial atoms $\mathrm{Si}$ is much more than number of pairs, at high temperatures their contribution to diffusion flow becomes appreciable. Submitted on Fig. 1 (curve 3) the dependence of a diffusion constant on temperature experimentally was determined at temperatures above $1000^{\circ} \mathrm{C}$ and was extrapolated to lower temperatures ${ }^{[1]}$. Such extrapolation is not represented correct, as the contribution of isolated atoms $\mathrm{Si}$ in diffusion flow at low temperatures becomes inappreciable by virtue of low value of their diffusion constants.

It must be pointed out that as the $\mathrm{Si}$ atoms in a pair are not bound to one another by chemical covalent bond, the lifetime of this pair is not large and pairs do not make long-range migrations. But transiting small distances and collapsing, the pairs enrich this area of a crystal by $\mathrm{Si}$ atoms. At achievement of high concentration of interstitials the pairs are formed again. Thus at high supersaturation the excess concentration of interstitials is spread in depth of a crystal with a high effective diffusion coefficient.

At low saturation, when the quantity of pairs is not great, the transport is carried out only by isolated $\mathrm{Si}$ atoms, for which the diffusion constant is much below and has typical temperature dependence (Fig. 1, curve 1).

\section{CONCLUSION}

The apparent two groups of the data on coefficients of a high-temperature diffusion of $\mathrm{Si}$ atoms in silicon, distinguished on some orders of magnitude, are caused by a diffusion of silicon in two shapes. At low saturation $\mathrm{Si}$ atoms diffuse as isolated with a low diffusion constant (at $900^{\circ} \mathrm{C}$ coefficient $\mathrm{D}$ about $10^{-12}$ $\left.\mathrm{cm}^{2} \mathrm{sec}^{-1}\right)$. At high supersaturation $\mathrm{Si}$ atoms form an $\mathrm{Si}-\mathrm{Si}$ interstitial pair, having lower activation energy of a diffusion and accordingly higher diffusion coefficient $\left(\mathrm{D} \approx 10^{-7} \mathrm{~cm}^{2} \mathrm{sec}^{-1}\right.$ at $900^{\circ} \mathrm{C}$ ).

\section{ACKNOWLEDGMENT}

The researcher M. Jadan thanks the administration of his affiliation: Tafila Technical University for its support in preparing this article.

\section{REFERENCES}

1. Tan, T.Y. and U. Gosele, 1985. Point defects, diffusion processes and swirl defect formation in silicon. Applied Phys. A., 37: 1-17. DOI: 10.1007/BF00617863

2. Bronner, G.B. and J.D. Plummer, 1987. Gettering of gold in silicon: A tool for understanding the properties of silicon interstitials. J. Applied Phys., 61: 5286-5298. DOI: 10.1063/1.338264

3. Zimmermann, H. and H. Ryssel, 1992. Gold and platinum diffusion: The key to the understanding of 
intrinsic point defect behavior in silicon. Applied Phys. A., 55: 121-134. DOI: 10.1007/BF00334210

4. Lecrosnier, D., M. Gannean, J. Pangam, G. Pelous, F. Richou and P. Renoc, 1979. Long-range enhancement of boron diffusivity induced by a high-surface-concentration phosphorus diffusion. Applied Phys. Lett., 34: 224-226. DOI: 10.1063/1.90738

5. Car, R., P.J. Kelly, A. Oshigama and S.T. Pantelides, 1984. Microscopy theory of atomic diffusion mechanisms in silicon. Phys. Rev. Lett., 52: 1814-1817. DOI: 10.1103/PhysRevLett.52.1814

6. Taniguchi, K., D.A. Antoniadis and Y. Matsushita, 1983. Kinetica of self-interstitials generated at the Si/SiO2 interface. Applied Phys. Lett., 42: 961-963. DOI: $10.1063 / 1.93814$

7. Griffin, P.B., P.M. Fahey, J.D. Plummer and R.W. Dutton, 1985. Measurement of silicon interstitial diffusivity. Applied Phys. Lett., 47: 319-321. DOI: 10.1063/1.96205

8. Taniguchi, K. and D.A. Antoniadis, 1985. Lateral extent of oxidation-enhanced diffusion of phosphorus in <100> silicon. Applied Phys. Lett., 46: 944-946. DOI: 10.1063/1.95829

9. Gossmann, H.J., C.S. Rafferty, H.S. Luftman, F.C. Unterwald, T. Boone and J.M. Poate, 1993. Oxidation enhanced diffusion in $\mathrm{Si}$ B-doping superlattices and $\mathrm{Si}$ self-interstitial diffusivities. Applied Phys. Lett., 63: 639-641. DOI: 10.1063/1.109975

10. Van Oostrum, K.J., P.C. Zalm, W.B. De Boer, D.J. Gravesteijn and J.W.F. Maers, 1992. Characterization of epitaxial layers by the depth dependence of boron diffusivity. Applied Phys. Lett., 61: 1513-1515. DOI: 10.1063/1.107533

11. Griffin, P.B., S.T. Ahn, W.A. Tiller and J.D. Plummer, 1987. Model for bulk effects on $\mathrm{Si}$ interstitial diffusivity in silicon. Applied Phys. Lett., 51: 115-117. DOI: $10.1063 / 1.98996$

12. Gossmann, H.J., G.H. Gilmer, C.S. Rafferty, F.C. Unterwald, T. Boone, H.S. Luftman and W. Frank, 1995. Determination of $\mathrm{Si}$ self-interstitial diffusivities from the oxidation-enhanced diffusion in B doping-superlattices: The influence of the marker layers. J. Applied Phys., 77: 1948-1951. DOI: $10.1063 / 1.358828$
13. Morehead, F.F. and R.F. Lever, 1986. Enhanced "tail" diffusion of phosphorus and boron in silicon: Self-interstitial phenomena. Applied Phys. Lett., 48: 151-153. DOI: 10.1063/1.96980

14. Chelyadinskii, A.R. and H.I. Haki Taher, 1994. Diffusion of ion-implanted phosphorus in silicon. Phys. Stat. Sol. A., 142: 331-338. DOI: 10.1002/pssa.2211420205

15. Chelyadinskii, A.R. and V.A. Burenkov, 1998. Model of pair phosphorus atom-interstitial silicon atom. Phys. Solid State, 40: 1806-1808. DOI: 10.1134/1.1130661

16. Lee, Y.H., N.N. Gerasimenko and J.W. Corbett, 1976. EPR study of neutron-irradiated silicon: A positive charge state of the $\langle 100\rangle$ split diinterstitial. Phys. Rev. B., 14: 4506-4510. DOI: 10.1103/PhysRevB.14.4506

17. Brower, K.L., 1976. EPR of a $<100>$ Si interstitial complex in irradiated silicon. Phys. Rev. B., 14: 872-883. DOI: 10.1103/PhysRevB.14.872

18. Lee, Y.H., Y.M. Kim and J.W. Corbett, 1972. New EPR spectra in neutron-irradiated silicon. Radiat. Effects, 15: 77-82. DOI: $10.1080 / 00337577208232584$

19. Corbett, J.W., J.P. Karins and T.Y. Tan, 1981. Ioninduced defects in semiconductors. Nucl. Instr. Meth., 182/183: 457-476. DOI: 10.1016/0029554X(81)90717-5

20. Chik, K.P., 1970. Doping effects on diffusion and diffusion mechanisms in $\mathrm{Ge}$ and $\mathrm{Si}$. Radiat. Effects, $\quad 4$ : 33-37. DOI: 10.1080/00337577008234961

21. Damask, A.C. and G.J. Dienes, 1964. Point Defects in Metals. Gordon and Breach Science Publishers, New York, London, ISBN: 0677001908, pp: 328. 